\title{
Piramo e Tisbe, a cura di Cristina Noacco
}

\author{
Maria Colombo Timelli
}

\section{(2) OpenEdition}

\section{Journals}

\section{Edizione digitale}

URL: http://journals.openedition.org/studifrancesi/29938

DOI: 10.4000/studifrancesi.29938

ISSN: 2421-5856

\section{Editore}

Rosenberg \& Sellier

\section{Edizione cartacea}

Data di pubblicazione: 1 avril 2006

Paginazione: 127

ISSN: 0039-2944

\section{Notizia bibliografica digitale}

Maria Colombo Timelli, «Piramo e Tisbe, a cura di Cristina Noacco», Studi Francesi [Online], 148 (XLX I

I) | 2006, online dal 30 novembre 2015, consultato il 19 avril 2021. URL: http://

journals.openedition.org/studifrancesi/29938 ; DOI: https://doi.org/10.4000/studifrancesi.29938

Questo documento è stato generato automaticamente il 19 avril 2021.

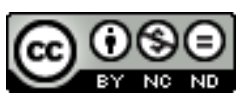

Studi Francesi è distribuita con Licenza Creative Commons Attribuzione - Non commerciale - Non opere derivate 4.0 Internazionale. 


\title{
Piramo e Tisbe, a cura di Cristina Noacco
}

\author{
Maria Colombo Timelli
}

\section{NOTIZIA}

Piramo e Tisbe, a cura di CRISTINA NOACCO, Roma, Carocci, 2005 (« Biblioteca Medievale », 102), pp. 110.

Il più antico dei rifacimenti ovidiani, composto attorno al 1160, Piramo $e$ Tisbe riprende, adattandolo all'etica e all'estetica del XII secolo, il celebre mito delle Metamorfosi IV, 55-166. Come ben sottolinea Cristina Noacco nell'introduzione al testo, l'autore applica alla sua fonte un'amplificatio che si attua sull'analisi psicologica dei personaggi, sull'estensione dello spazio e sulla precisazione della durata; ma il vero problema è la giustificazione del duplice suicidio, spiegato dalla passione amorosa e soprattutto situato in un contesto pagano. Ancora, nel rifacimento medievale, il racconto eziologico - il mito all'origine del colore dei frutti del gelso - si trasforma in una narrazione in cui la metamorfosi è solo il corollario di una storia d'amore leale oltre ogni limite. L'introduzione affronta anche, in poche dense pagine, la questione dell'enorme fortuna della storia in area non solo francese: numerosissimi sono infatti i riferimenti intertestuali, le riprese, gli adattamenti (si pensi solo all'Ovide moralisé, in versi e in prosa); e persino il modus narrandi del Lai diventa modello per altri testi, con la ripresa di immagini e di modalità espressive quali il monologo e il monologo dialogato.

2 Una rapidissima "Nota al testo" (pp. 39-40) rende conto della tradizione del Lai: tre manoscritti, cui si aggiungono i 19 dell'Ovide moralisé, e tre manoscritti e due incunaboli dell'Ovide moralisé in prosa. La "Nota bibliografica" (pp. 41-45) segnala le edizioni principali del Piramus et Tisbé e la bibliografia secondaria di base. L'edizione segue quella di C. De Boer («CFMA», Parigi, 1921) con due piccoli emendamenti ai vv. 236 e 907; la traduzione in italiano, a fronte, è fedele senza cadere negli eccessi del "mot à 
mot"; l'apparato delle note (pp. 96-110) si rivela utile e filologicamente fondato, pur nello spirito della collana, destinata anche ai non specialisti. 